\title{
Variability in connectivity indicated by chaotic genetic patchiness within and among populations of a marine fish
}

\author{
J. Derek Hogan ${ }^{1,2, *}$, Roger J. Thiessen ${ }^{1}$, Daniel D. Heath ${ }^{1}$ \\ ${ }^{1}$ Great Lakes Institute for Environmental Research, University of Windsor, Windsor, Ontario N9B 3P4, Canada \\ ${ }^{2}$ Present address: Department of Ecology and Evolutionary Biology, Tulane University, New Orleans, Louisiana 70118, USA
}

\begin{abstract}
Despite substantial advances in our understanding of marine population dynamics, there is still much uncertainty as to what processes influence connectivity, gene flow and population structure. To explore this, we examined the spatial and temporal variation in population genetic structure of adult and recently settled bicolor damselfish Stegastes partitus, a coral reef fish. We genotyped adult and juvenile fish from 10 sites over 4 sample years at 9 microsatellite loci. We show spatial heterogeneity in adult and juvenile population structure; however, we found no evidence of a pattern of spatial genetic divergence. Furthermore, genetic structure changed through time and between life stages in an unpredictable manner. Using these data, we test whether pre- or postsettlement selection, sweepstakes effects or variability in connectivity can explain the observed chaotic genetic patchiness. Our results indicate that the contributions of various larval sources likely change through time as a result of stochastic processes such as oceanographic flow. Our results have implications for the management of marine populations, as spatial and temporal variability in connectivity may act to promote long term stability of populations. Therefore it is important that marine management efforts account for such heterogeneity in the design of protected areas.
\end{abstract}

KEY WORDS: Connectivity · Temporal variability · Larval dispersal · Chaotic genetic patchiness · Genetic structure $\cdot$ Coral reef fish

\section{INTRODUCTION}

Many marine organisms have a pelagic larval phase giving them great dispersal potential, and this has implications for populations on evolutionary and ecological scales. Dispersal will lead to connectivity and gene flow among populations, and is expected to lead to genetic homogenization (Wright 1931) and influence local adaptive processes (Bradbury et al. 2008). Dispersive larvae will replenish populations and the variation in the timing and magnitude of larval supply can have a strong influence on adult population sizes (Doherty \& Williams 1988). Despite the importance of pelagic larvae to the ecology and evolution of marine populations, marine scientists are only starting to understand the factors that affect the abundance and distribution of marine larvae (Cowen et al. 2007, Jones et al. 2009). This paucity of information is a major obstacle to better understanding of population dynamics of marine organisms (Cowen et al. 2007).

Population genetics is a very powerful tool to investigate factors that affect the larval supply and connectivity among populations, and has been applied successfully to marine systems in the past (see reviews by Larson \& Julian 1999, Hedgecock et al. 2007). Given the high reproductive output and high dispersive potential of most marine species, it is logical to infer genetic homogenization among populations (Waples 1987, Ward et al. 1994, Shulman \& Bermingham 1995, Hilbish 1996). However, some studies have found contradictory results, showing fine-scale genetic heterogeneity both 
through time and space (Larson \& Julian 1999). This fine-scale genetic heterogeneity, termed chaotic genetic patchiness (Johnson \& Black 1982), is characterized by low level genetic differentiation among and between adult and recruit populations (i.e. low $F_{\mathrm{ST}}$ ) that is not consistent in space or time (Johnson \& Black 1984).

There are 4 main hypotheses put forth to explain chaotic genetic patchiness (Larson \& Julian 1999); each infers a different mechanism by which this pattern can be explained. These hypotheses are (1) localized postsettlement selection resulting from microgeographic variation in environmental conditions, (2) variable local natural selection on pre-settlement individuals generating variability in cohorts through space and time, (3) 'sweepstakes chance-matching' (Hedgecock 1994) created by variable reproductive success of the adult source populations as a result of stochastic processes. This causes a genetic drift effect during the larval stage and a subsequent reduction in genetic variability in the recruit populations, and (4) spatial and temporal variability in the genetic composition of recruits caused by fluctuations in the source of larvae (Selkoe et al. 2006).

Post-settlement natural selection has been invoked to explain spatial genetic heterogeneity in a marine snail (Johannesson et al. 1995). Generally, however, most studies have shown that genetic composition is variable through time, and that it is likely attributable to pre-settlement factors causing genetically variable larval cohorts (e.g. Johnson \& Black 1984, Watts et al. 1990, Hedgecock 1994, Purcell et al. 1996, Selkoe et al. 2006). Johnson \& Black (1984) found that pre-settlement natural selection on pelagic larvae had led to genetic variation among recruits in the intertidal limpet Siphonaria sp., where recruit genotypes varied through time and were correlated with environmental conditions. However, Hedgecock (1994) compiled evidence across a variety of taxa that supports the sweepstakes hypothesis. Finally, pre-settlement variation in recruit composition driven by the mixing of sub-populations in the plankton (evidence for the variable source hypothesis) was suggested to explain temporal patchiness in haddock (Purcell et al. 1996), as well as to explain small-scale variation in Stegastes partitus populations using allozyme and microsatellite markers (Lacson \& Morizot 1991, Roberts 1997, Hepburn et al. 2009).

Since the 4 hypothesized mechanisms for fine-scale genetic heterogeneity generate specific predictions at the juvenile and adult life stages, an examination of both life stages over various spatial and temporal scales will provide valuable insight into population genetic structure in marine organisms with high dispersal capacity. We chose the bicolor damselfish Stegastes partitus as a model organism to examine genetic structure among populations over time. S. partitus is a demersally spawning damselfish common throughout the Caribbean with a larval duration of approximately $30 \mathrm{~d}$. It thus has a moderate to high dispersal capacity and is expected to show limited or no spatial genetic structure. Genetic structure and stability of $S$. partitus populations has been assessed using variable allozyme markers, and both fine-scale population structuring and temporal instability were demonstrated (Lacson et al. 1989, Lacson \& Morizot 1991). However, this population structuring was driven by a single allozyme locus that appeared to be under selection and structuring was attributed to a previous bottleneck event (Lacson \& Morizot 1991). Using microsatellite markers, studies have shown both weak population structuring (Hepburn et al. 2009, Purcell et al. 2009, Salas et al. 2009) and panmixia (OspinaGuerrero et al. 2008). Furthermore, chaotic genetic patchiness has been previously shown within and among populations of $S$. partitus in the Bahamas (Christie et al. 2010). The authors attributed genetic patchiness in that case to sweepstakes effects.

Here we use 9 neutral microsatellite markers to assess population genetic structure at 10 sites along $\sim 200 \mathrm{~km}$ of the Mesoamerican Barrier Reef System (MBRS). We repeated sampling at these sites over $4 \mathrm{yr}$ and collected adult and recently settled juvenile Stegastes partitus at each site. We assess population genetic structure in both adult and early juvenile life stages across years. We use these data to test hypotheses to explain patchy, transient genetic structure among these populations, and we discuss the results in terms of their implications for marine management.

\section{MATERIALS AND METHODS}

Study species. Stegastes partitus is a small, territorial, damselfish (Pomacentridae) common on reefs throughout the tropical western Atlantic. Adults spawn demersally following a unimodal lunar cycle with seasonal reproductive peaks from April to November, although spawning does occur throughout the year (Robertson et al. 1988). The males of the species provide care for the eggs, however after hatching ( 3.5 d) larvae enter the pelagic environment and the pelagic larval duration is 24 to 40 d (Robertson et al. 1988, Wellington \& Victor 1989, J. D. Hogan unpubl. data). After settlement the adults are sedentary, defending small feeding territories indefinitely (Myrberg 1972). This life history allows us to examine the genetic population structure of this species where connectivity and gene flow between reefs is determined exclusively by larval dispersal.

Field sampling. Adult and recently settled juvenile individuals were sampled by divers from 10 fore-reef sites (Fig. 1) at a depth of $\sim 10 \mathrm{~m}$. The area of sampling 
at each site was $\sim 8000 \mathrm{~m}^{2}$. Adult individuals (>40 mm fork length) were selected by eye, as fish were found to be mature above $38 \mathrm{~mm}$ (R. J. Thiessen unpubl. data). Juveniles were identified as being less than $25 \mathrm{~mm}$ fork length, corresponding to an estimated age of less than 2 wk post-settlement (Hogan 2007). Approximately 100 adults and 50 to 100 juveniles were collected at each site in all years (totaling 2522 adult and 1772 juvenile fish). Each site was sampled in 2005, 2006, 2007 and 2008 with some exceptions due to logistical issues: (1) the Mexico site sampled in 2005 (M05, Fig. 1) could not be sampled in 2006, so a site was chosen further north for 2006 and 2007 (M, Fig. 1); however, no Mexican site could be sampled in 2008, (2) two additional sites were added in 2008 (Lighthouse Reef and Glovers Reef in Belize).

Sampling occurred from June 10 to July 5 in 2005, April 19 to 29 in 2006, May 19 to June 1 in 2007, and May 18 to June 3 in 2008. All fish were collected from a site in a single day except at east Turneffe in 2005, where adults were collected over a 2 wk period and juveniles were collected in $1 \mathrm{~d}$. Tissue samples (fin clips) for DNA extraction were preserved in $95 \%$ ethanol in 2005 and in a salt preservation solution (0.020 M EDTA, $0.025 \mathrm{M}$ sodium citrate trisodium salt dehydrate, $5.3 \mathrm{M}$ ammonium sulphate) for the remaining sampling years. Some of the adult samples, from 4 of our sampling sites from the 2006 collection year (M, BN, BS and E, Fig. 1), were previously used by Salas et al. (2010).

Genotyping. Genomic DNA was extracted from pectoral fin tissue of adult and juvenile individuals using a Wizard DNA extraction kit (Promega) for the 2005 samples, and following the silica-based 96-well plate protocol of Elphinstone et al. (2003) for the remaining samples. Nine microsatellite loci were chosen from Williams et al. (2003) and Thiessen \& Heath (2007) where locus specific primers were developed from clone sequences, and 3 of the loci were modified for size $\left(\operatorname{SpAAT}_{40}, S p \mathrm{AAC}_{44}, S p \mathrm{AAC}_{33}\right)$ to facilitate running multiple loci on the DNA analyzer. To modify these primers, clone sequences were taken from Genebank and primers were designed inside of the original published primers thereby creating smaller PCR amplicons. PCR amplification was then performed in $12.5 \mu \mathrm{l}$ reactions comprised of $100 \mathrm{ng}$ template DNA, $32 \mu \mathrm{M}$ of forward dye-label primer and $0.5 \mu \mathrm{M}$ of reverse primer, $200 \mu \mathrm{M}$ of each dNTPs, $0.1 \mathrm{U}$ Taq polymerase (Invitrogen), $1 \times$ PCR buffer (provided by the manufacturer), and locus specific concentrations of $\mathrm{MgCl}_{2}$. PCR conditions were $94^{\circ} \mathrm{C}$ for $2 \mathrm{~min}$, followed by 30 cycles of $94^{\circ} \mathrm{C}$ for $15 \mathrm{~s}$, locus specific annealing temperature (Table 1) for $15 \mathrm{~s}, 72^{\circ} \mathrm{C}$ for $30 \mathrm{~s}$, and a final extension of $72^{\circ} \mathrm{C}$ for $90 \mathrm{~s}$. The size of the PCR products was determined using a LiCor 4300 DNA Analyzer with GeneImagIR v4.05 software (Scanalytics).

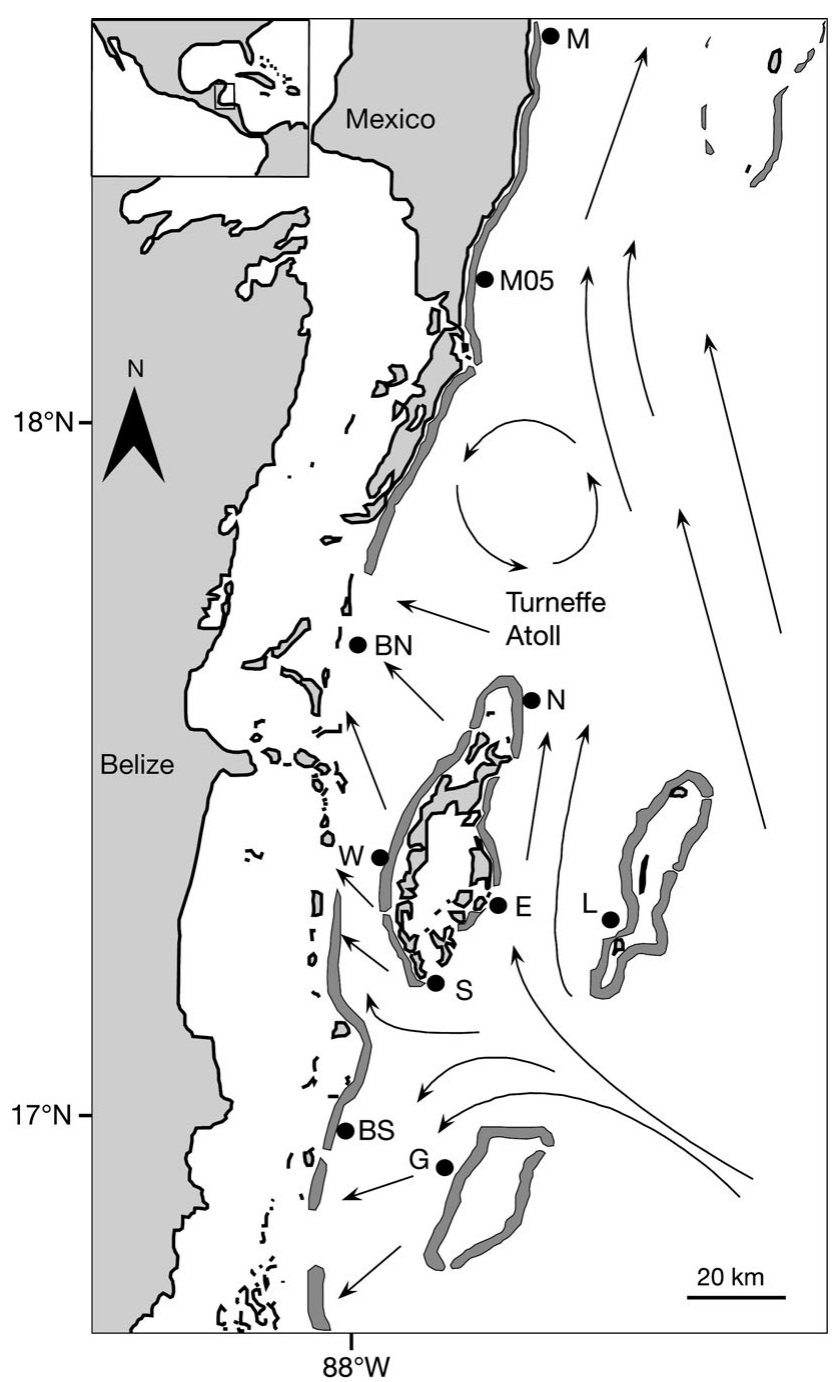

Fig. 1. Overview of the sampling sites within the Mesoamerican barrier reef system (MBRS). BN = barrier reef north, BS = barrier reef south, $\mathrm{N}=$ Turneffe Atoll north, $\mathrm{S}=$ Turneffe Atoll south, $\mathrm{E}=$ Turneffe Atoll east, $\mathrm{W}=$ Turneffe Atoll west, M05 = Mexico (2005), $M=$ Mexico (2006 \& 2007), L = Lighthouse Reef, $\mathrm{G}=$ Glovers Reef. Arrows indicate predominant flow in the region as modelled by Ezer et al. (2005)

Genetic analyses. Genotype data were separated into adult and juvenile life stages at each of the sampling sites. Exact tests for goodness of fit to HardyWeinberg equilibrium using the Markov Chain method (1000 permutation burn-in followed by 100000 permutations) for each locus within each adult and juvenile sample were performed in ARLEQUIN v3.11 (Excoffier et al. 2005), and results were adjusted for multiple comparisons using the sequential Bonferroni correction (Rice 1989). Tests for linkage disequilibrium were performed on all adult and juvenile site samples in GENEPOP v1.2 (Raymond \& Rousset 1995). Loci were tested for possible genotyping errors including 
Table 1. Summary statistics and reaction conditions for 9 microsatellite markers comparing adult and juvenile populations of Stegastes partitus over $4 \mathrm{yr}\left(\mathrm{n}=58\right.$ populations). Ta = locus specific annealing temperature. $\mathrm{MgCl}_{2}=$ locus specific concentrations of magnesium chloride used in PCR reactions. $H=$ percentage of populations that deviate from Hardy-Weinberg equilibrium. Ho $=$ average heterozygosity by locus across all adult and juvenile samples respectively. AR = average allelic richness values by locus across all adult and juvenile samples respectively

\begin{tabular}{|c|c|c|c|c|c|c|c|c|c|}
\hline \multirow[t]{2}{*}{ Locus } & \multirow{2}{*}{$\begin{array}{l}\text { Ta } \\
\left({ }^{\circ} \mathrm{C}\right)\end{array}$} & \multirow{2}{*}{$\begin{array}{c}\mathrm{MgCl}_{2} \\
(\mathrm{mM})\end{array}$} & \multirow{2}{*}{ Global $F_{\mathrm{ST}}$} & \multicolumn{3}{|c|}{ Adult samples } & \multicolumn{3}{|c|}{ Juvenile samples } \\
\hline & & & & $H(\%)$ & Ho & $\mathrm{AR}$ & $H(\%)$ & Ho & $\mathrm{AR}$ \\
\hline $\mathrm{SpGATA}_{40}$ & 48 & 10 & 0.001 & 62.0 & 0.85 & 25.7 & 44.8 & 0.87 & 25.6 \\
\hline $\mathrm{SpAAT}_{40}$ & 48 & 10 & 0.002 & 0.0 & 0.88 & 14.5 & 0.1 & 0.88 & 14.6 \\
\hline $\mathrm{SpAAC}_{44}$ & 48 & 10 & 0.044 & 44.8 & 0.34 & 7.7 & 44.8 & 0.33 & 7.7 \\
\hline$S p \mathrm{AAC}_{33}$ & 60 & 10 & 0.002 & 55.2 & 0.77 & 13.5 & 51.7 & 0.78 & 13.3 \\
\hline$S p \mathrm{TG}_{16}$ & 52 & 8 & 0.006 & 58.6 & 0.88 & 24.0 & 34.5 & 0.88 & 24.6 \\
\hline $\mathrm{SpGGA}_{7}$ & 48 & 10 & 0.025 & 48.3 & 0.55 & 5.2 & 24.1 & 0.56 & 5.1 \\
\hline$S p \mathrm{TG}_{53}$ & 48 & 6 & 0.002 & 31.0 & 0.89 & 25.7 & 13.8 & 0.88 & 25.1 \\
\hline$S p \mathrm{TG}_{13}$ & 49 & 10 & 0.018 & 41.4 & 0.65 & 6.7 & 41.4 & 0.64 & 6.5 \\
\hline$S p \mathrm{GT}_{10}$ & 55 & 10 & 0.003 & 31.0 & 0.83 & 13.5 & 31.0 & 0.83 & 13.1 \\
\hline
\end{tabular}

large allele drop-out and other molecular phenomena (i.e. null alleles) that could explain deviations from Hardy-Weinberg equilibrium (HWE) using MicroChecker v2.2.3 (Van Oosterhout et al. 2004).

Spatial and temporal population genetic structure. To quantify the extent of differentiation between populations within each year, pair-wise $F_{\mathrm{ST}}$ values were calculated and tested for significance using permutation tests, with 10000 bootstrap iterations, in MSA 4.05 (Dieringer \& Schlötterer 2003). Also, pair-wise exact tests for differences in allele frequency and genotype frequency distributions between populations were performed in GENEPOP v1.2. Given that our loci are highly polymorphic (Table 1), and that $F_{\mathrm{ST}}$ tends to underestimate differentiation when heterozygosity is high, we also calculated a standardized measure of $F_{\mathrm{ST}}$ (Jost's $D_{\text {ESTi }}$ Jost 2008) in SMOGD v1.2.5 (Crawford 2010) using 500 bootstrap replicates and we used the harmonic mean of $D_{\text {EST }}$ across loci. Cavalli-Sforza \& Edwards' (1967) chord distance $\left(D_{\mathrm{C}}\right)$ was calculated to estimate pair-wise genetic distance between all populations, both within and across years, as was allelic richness, using MSA 4.05 (Dieringer \& Schlötterer 2003). We used the Bonferroni method to correct for the effect of multiple tests in all instances above.

We tested for spatial patterning in genetic differentiation $\left(F_{\mathrm{ST}}, D_{\mathrm{EST}}\right)$ and genetic distance $\left(D_{\mathrm{C}}\right)$ among adult samples at our reefs. We performed Mantel tests in GENALEX (Peakall \& Smouse 2006) to test for correlations of $F_{\mathrm{ST}}, D_{\mathrm{EST}}$ and $D_{\mathrm{C}}$ with shortest water distance (km) among sample sites (i.e. isolation by distance) within years. Patterns were consistent between measures of pair-wise population divergence, so only $D_{\mathrm{C}}$ values are reported due to their relative insensitivity to departures from HWE (Cavalli-Sforza \& Edwards 1967). We also performed a principal coordinate analysis (PCoA) in GENALEX (Peakall \& Smouse 2006) to investigate spatial and temporal patterning in genetic differentiation among our adult samples. We used pairwise $F_{\mathrm{ST}}$ as our measure of genetic differentiation between reefs in the PCoA.

Temporal stability within sites was assessed by 2 methods. First, exact tests were used to test for changes in allelic distribution in the adult samples within each sample site across consecutive years. Second, the stability of among-site genetic structure was assessed by testing for a correlation between adult pair-wise population divergence between consecutive years, measured with $F_{\mathrm{ST}}, D_{\mathrm{EST}}$ and $D_{\mathrm{C}}$ values, using a Mantel test in GENALEX. High genetic stability should result in a strong correlation between pair-wise genetic divergence in consecutive years.

Explaining chaotic genetic patchiness. To test whether pre- or post-settlement selection may be explaining chaotic genetic patchiness, we tested for the effects of selection on our loci using the Beaumont \& Nichols (1996) algorithm in LOSITAN (Antao et al. 2008). We performed 95000 simulations of the algorithm assuming an infinite alleles model. Since the number of true populations in our study system was not apparent from population genetic data, we ran replicate runs in LOSITAN assuming between 2 and 5 true populations. We analysed adult and juvenile populations separately.

To test generally for pre-settlement effects, the temporal stability of juvenile samples between years, as well as the correlation between juvenile population structure and adult population structure in consecutive years, was assessed (as described above). Exact tests were used to test for changes in allelic distribution in the juvenile samples within each sample site across consecutive years. Exact tests were also used to compare the allelic distribution of juvenile samples to their corresponding adult samples. Finally, a correlation between adult and juvenile genetic structure was performed. If pre-settlement factors play a role in generat- 
ing patterns of chaotic genetic patchiness we expect to see temporal variability in juvenile genetic structure and discordance between adult and juvenile population structure.

To test for sweepstakes effects we compared the average heterozygosity and allelic richness across loci between adult and juvenile samples (Systat v10). If sweepstakes effects are driving these patterns, juvenile samples would be expected to show lower levels of diversity than adult samples because the juveniles are produced by only a subset of the adult populations. We also compared mean pair-wise relatedness between adult and juvenile samples using 2 different measures; Queller \& Goodnight (1989) and Lynch \& Ritland (1999), both calculated in GENALEX. We expect that, if sweepstakes effects are occurring, within-sample juvenile relatedness will be greater than relatedness within adult samples. We used Student's $t$-test to test for a difference in the mean within-sample relatedness (Statistica v6). We also performed linear regression of mean pair-wise $D_{\mathrm{C}}$ values in the adult samples against mean within-population relatedness for all juvenile populations with all years combined. If population genetic structure were driven by sweepstakes effects, one would expect juveniles to be more related in genetically differentiated populations, as the observed differentiation would be the result of an influx of juveniles produced by a discrete subset of offspring from an adult population.

To test for support for the variable source hypothesis we analysed our data for a Wahlund effect. A Wahlund effect is created by the pooling of samples from subpopulations with different allele frequencies and is typified by heterozygote deficiency. If sites are receiving cohorts of juveniles from variable sources then we would expect to see widespread deviations from HWE as a result of heterozygote deficits. Furthermore, since a given sample from a site is a mixture of successive cohorts from multiple sources, then dividing the samples into size classes should reduce the heterozygote deficiencies and thus the deviations from HWE. To test for a Wahlund effect we analysed our data by dividing the adult and juvenile samples into large and small size classes. We then analysed these samples for goodness of fit to HWE in Arlequin v3.11 (Excoffier et al. 2005) as described above.

\section{RESULTS}

\section{Genetic analyses}

Adult and juvenile samples showed significant deviations from Hardy-Weinberg equilibrium HWE, at various loci, in $42,37,37$ and $31 \%$ of tests (prior to Bonfer- roni correction) in 2005, 2006, 2007 and 2008 respectively (in the supplement at www.int-res.com/articles/ suppl/m417p263_supp.pdf, Table S1). All loci showed deviations from HWE in at least 1 sample, although locus $\mathrm{AAT}_{40}$ deviated only once in 58 population samples. Homozygote excesses were found at all loci, which overwhelmingly explained deviations from HWE in multiple sample populations at these loci (Tables S1 \& S2). Micro-Checker showed that homozygote excesses were not attributable to genotyping errors such as large allele drop-out, but null alleles could not be ruled out as causing a general excess of homozygotes at multiple alleles in these loci. However, this pattern can also be created by genetic drift and/or a Wahlund effect due to mixing of individual cohorts or generations. Furthermore, if homozygote excesses were attributable solely to null alleles then we would not expect to see significant temporal variation in the prevalence of homozygote excesses, as was clearly indicated in our data (Table S1).

An analysis of HWE in adult versus juvenile samples showed that the number of departures from HWE in the adult samples was 104, while the comparable number for the juvenile samples was 82; this difference was marginally significant $\left(\chi^{2}=3.6, \mathrm{df}=1, \mathrm{p}=0.058\right)$. Approximately $2.5 \%$ (55 of 2088) of exact tests showed significant linkage disequilibrium between loci over the 4 years sampled (Table S2).

\section{Spatial and temporal population genetic structure}

Across all years, adult $F_{\mathrm{ST}}$ values were low (range: -0.001 to 0.02 ), but 32 of 91 pair-wise comparisons showed $F_{\mathrm{ST}}$ values significantly greater than zero (Table 2). Furthermore, 92\% of pair-wise exact test comparisons showed significant differences in allelic frequency distribution between adult populations (Table 2) and $79 \%$ of exact tests showed significant differences in genotype frequency between adult populations. There were no significant $F_{\text {ST }}$ values among populations in 2006, however, exact tests did indicate differences in allelic composition among these samples. Adult pair-wise $D_{\text {EST }}$ values were also low, across all years (range: 0.00 to 0.03 ), and not strikingly different from the $F_{\mathrm{ST}}$ values reported. Therefore, the low level differentiation we observed here is not strongly influenced by the high level of polymorphisms among our loci.

Despite the fact that there was significant genetic structure among adult samples, Mantel tests indicated that there was no isolation by distance pattern among adult samples in any of the sampled years (Mantel tests, 2005: $\mathrm{p}=0.18,2006: \mathrm{p}=0.06,2007: \mathrm{p}=0.46,2008 \mathrm{p}=$ $0.10)$. The same general pattern holds true of tests per- 
Table 2. Stegastes partitus adults. $F_{\mathrm{ST}}$ values (below diagonal) and $D_{\mathrm{C}}$ values with significance of exact tests (above diagonal) for adult populations from sampling sites within the MBRS (see Fig. 1 for site abbreviations). Significant values indicated in bold and underlined. Negative $F_{\mathrm{ST}}$ values are not significantly different from zero

\begin{tabular}{|c|c|c|c|c|c|c|c|c|c|}
\hline & & $\mathrm{BN}$ & BS & $\mathrm{N}$ & $\mathrm{S}$ & E & W & $\mathrm{M}$ & \\
\hline \multirow[t]{7}{*}{2005} & $\mathrm{BN}$ & - & $\underline{0.280}$ & $\underline{0.221}$ & $\underline{0.224}$ & $\underline{0.238}$ & $\underline{0.211}$ & $\underline{0.244}$ & \\
\hline & BS & $\underline{0.015}$ & - & $\underline{0.246}$ & $\underline{0.246}$ & $\underline{0.250}$ & $\underline{0.252}$ & $\underline{0.289}$ & \\
\hline & $\mathrm{N}$ & $\underline{0.012}$ & $\underline{0.006}$ & - & $\underline{0.193}$ & $\underline{0.192}$ & $\underline{0.210}$ & $\underline{0.216}$ & \\
\hline & $\mathrm{S}$ & $\underline{0.011}$ & 0.006 & 0.002 & - & $\underline{0.195}$ & $\underline{0.199}$ & $\underline{0.217}$ & \\
\hline & $\mathrm{E}$ & $\underline{0.013}$ & 0.005 & 0.001 & 0.000 & - & $\underline{0.208}$ & $\underline{0.222}$ & \\
\hline & W & $\underline{0.009}$ & $\underline{0.008}$ & 0.006 & 0.003 & 0.006 & - & 0.224 & \\
\hline & $\mathrm{M}$ & $\overline{\mathbf{0 . 0 1 3}}$ & $\overline{0.012}$ & 0.003 & 0.005 & $\underline{0.007}$ & 0.006 & $\overline{-}$ & \\
\hline \multirow[t]{7}{*}{2006} & BN & - & $\underline{0.219}$ & $\underline{0.225}$ & $\underline{0.225}$ & $\underline{0.217}$ & $\underline{0.216}$ & $\underline{0.208}$ & \\
\hline & BS & 0.000 & - & $\overline{0.196}$ & $\overline{0.208}$ & $\overline{0.227}$ & $\underline{0.216}$ & $\underline{0.195}$ & \\
\hline & $\mathrm{N}$ & 0.001 & 0.001 & - & $\underline{0.196}$ & $\overline{0.218}$ & $\overline{0.205}$ & $\overline{0.184}$ & \\
\hline & $\mathrm{S}$ & 0.000 & 0.000 & 0.000 & - & $\overline{0.198}$ & $\underline{0.209}$ & $\underline{0.191}$ & \\
\hline & $\mathrm{E}$ & 0.001 & 0.002 & 0.000 & 0.000 & - & 0.221 & 0.197 & \\
\hline & $\mathrm{W}$ & 0.001 & 0.001 & 0.000 & 0.001 & 0.001 & - & 0.204 & \\
\hline & $\mathrm{M}$ & 0.000 & 0.001 & 0.001 & 0.000 & 0.001 & 0.003 & $\overline{-}$ & \\
\hline \multirow[t]{8}{*}{2007} & $\mathrm{BN}$ & - & $\underline{0.238}$ & $\underline{0.219}$ & $\underline{0.234}$ & $\underline{0.228}$ & $\underline{0.228}$ & $\underline{0.209}$ & \\
\hline & BS & $\underline{0.011}$ & - & 0.281 & 0.226 & $\underline{0.218}$ & 0.239 & 0.214 & \\
\hline & $\mathrm{N}$ & 0.004 & $\underline{0.020}$ & - & $\underline{0.260}$ & $\underline{0.256}$ & $\underline{0.256}$ & 0.241 & \\
\hline & $\mathrm{S}$ & $\underline{0.013}$ & $\underline{0.008}$ & $\underline{0.020}$ & - & $\underline{0.204}$ & $\underline{0.212}$ & $\underline{0.220}$ & \\
\hline & $\mathrm{E}$ & $\underline{0.007}$ & $\overline{0.002}$ & $\underline{0.012}$ & 0.004 & - & $\underline{0.230}$ & $\underline{0.202}$ & \\
\hline & $\mathrm{W}$ & $\underline{0.006}$ & $\underline{0.007}$ & 0.014 & 0.003 & $\underline{0.006}$ & - & 0.234 & \\
\hline & $\mathrm{M}$ & $\overline{0.005}$ & $\overline{0.004}$ & $\underline{0.009}$ & $\underline{0.014}$ & $\overline{0.000}$ & $\underline{0.010}$ & - & \\
\hline & & $\mathrm{BN}$ & BS & $\mathrm{N}$ & $\mathrm{S}$ & E & W & $\mathrm{L}$ & G \\
\hline \multirow[t]{8}{*}{2008} & $\mathrm{BN}$ & - & 0.203 & 0.203 & $\underline{0.227}$ & $\underline{0.220}$ & $\underline{0.224}$ & $\underline{0.227}$ & $\underline{0.236}$ \\
\hline & BS & 0.000 & - & $\underline{0.208}$ & $\overline{0.199}$ & $\overline{0.203}$ & $\overline{0.205}$ & $\overline{0.203}$ & $\underline{0.214}$ \\
\hline & $\mathrm{N}$ & -0.001 & 0.001 & $\overline{-}$ & $\overline{0.208}$ & $\overline{0.214}$ & $\overline{0.210}$ & $\overline{0.223}$ & $\overline{0.236}$ \\
\hline & $\mathrm{S}$ & 0.004 & 0.002 & 0.004 & - & $\overline{0.200}$ & $\overline{0.222}$ & $\overline{0.219}$ & $\overline{0.213}$ \\
\hline & $\mathrm{E}$ & 0.005 & 0.003 & $\underline{0.006}$ & 0.004 & $\overline{-}$ & $\overline{0.225}$ & $\overline{0.217}$ & $\overline{0.199}$ \\
\hline & $\mathrm{W}$ & 0.002 & 0.002 & $\overline{0.002}$ & 0.003 & $\underline{0.005}$ & - & 0.223 & $\underline{0.235}$ \\
\hline & $\mathrm{L}$ & $\underline{0.007}$ & 0.007 & $\underline{0.008}$ & 0.007 & 0.005 & 0.007 & - & 0.224 \\
\hline & $\mathrm{G}$ & $\underline{0.008}$ & 0.004 & $\underline{0.009}$ & $\underline{0.005}$ & -0.001 & $\underline{0.008}$ & 0.005 & - \\
\hline
\end{tabular}

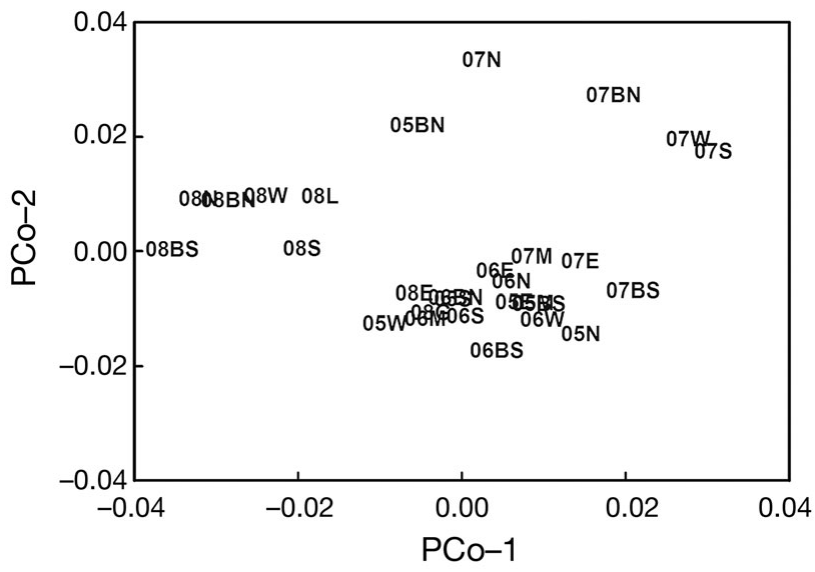

Fig. 2. Spatial and temporal variation in genetic structure of adult populations of Stegastes partitus as indicated by the results of a PCoA. We used pair-wise $F_{\mathrm{ST}}$ as a measure of genetic differentiation to construct the PCoA. The site codes used are the same as in Fig. 1; a 2-digit numeral is also used to indicate the year of sampling for each site formed using $D_{\mathrm{EST}}(2005: \mathrm{p}=0.05,2006: \mathrm{p}=0.04,2007$ : $\mathrm{p}=0.37,2008: \mathrm{p}=0.21)$. In 2006 there was a significant decrease in $D_{\text {EST }}$ with distance $\left(\mathrm{r}^{2}=0.20, \mathrm{p}=0.04\right)$, which is counter-intuitive, and the overall pattern showed that there was generally no IBD among the populations. PCoA of adult population structure supported the above findings; there was weak spatial structuring of adult populations with no clear spatial patterning within years, and also high levels of temporal variation in genetic structure between years (Fig. 2).

Among juvenile samples, $F_{\mathrm{ST}}$ values were also low (range: -0.002 to 0.035 ). Eleven of 91 pair-wise $F_{\mathrm{ST}}$ comparisons were significantly greater than zero across all years (Table 3), 75\% of exact tests showed significant differences in allele frequency distribution between juvenile samples (Table 3 ), and $62 \%$ of exact tests showed significant differences in genotype frequency distribution between samples. Almost all significant pair-wise $F_{\mathrm{ST}}$ comparisons among juvenile samples occurred in 2007. 
Table 3. Stegastes partitus juveniles. $F_{\mathrm{ST}}$ values (below diagonal) and $D_{\mathrm{C}}$ values with significance of exact tests (above diagonal) for juvenile populations of $S$. partitus from sites within the MBRS (see Fig. 1 for site abbreviations). Significant values indicated in bold and underlined. Negative $F_{\mathrm{ST}}$ values are not significantly different from zero

\begin{tabular}{|c|c|c|c|c|c|c|c|c|c|}
\hline & & $\mathrm{BN}$ & BS & $\mathrm{N}$ & S & $\mathrm{E}$ & $\mathrm{W}$ & M & \\
\hline \multirow[t]{7}{*}{2005} & $\mathrm{BN}$ & - & $\underline{0.286}$ & 0.264 & $\underline{0.242}$ & 0.232 & $\underline{0.282}$ & 0.252 & \\
\hline & BS & 0.008 & - & $\underline{0.286}$ & 0.280 & $\underline{0.297}$ & $\underline{0.284}$ & 0.264 & \\
\hline & $\mathrm{N}$ & -0.001 & 0.002 & - & 0.257 & 0.259 & $\underline{0.288}$ & 0.255 & \\
\hline & $\mathrm{S}$ & 0.003 & 0.009 & 0.001 & - & 0.260 & $\overline{0.246}$ & 0.233 & \\
\hline & $\mathrm{E}$ & -0.001 & 0.007 & -0.002 & 0.002 & - & $\underline{0.272}$ & 0.243 & \\
\hline & W & $\underline{0.012}$ & 0.009 & 0.005 & 0.003 & 0.011 & - & $\underline{0.261}$ & \\
\hline & M & 0.000 & 0.002 & 0.000 & -0.001 & 0.000 & 0.007 & - & \\
\hline \multirow[t]{7}{*}{2006} & $\mathrm{BN}$ & - & $\underline{0.265}$ & $\underline{0.273}$ & $\underline{0.274}$ & $\underline{0.273}$ & 0.259 & $\underline{0.265}$ & \\
\hline & BS & 0.005 & - & 0.243 & $\underline{0.251}$ & $\underline{0.268}$ & $\underline{0.262}$ & 0.236 & \\
\hline & $\mathrm{N}$ & 0.006 & -0.001 & - & $\underline{0.269}$ & $\underline{0.286}$ & $\underline{0.260}$ & $\underline{0.258}$ & \\
\hline & $\mathrm{S}$ & 0.005 & 0.001 & 0.004 & - & $\underline{0.292}$ & $\underline{0.259}$ & $\underline{0.270}$ & \\
\hline & $\mathrm{E}$ & 0.010 & 0.003 & 0.003 & 0.008 & - & $\underline{0.288}$ & 0.245 & \\
\hline & W & 0.001 & 0.006 & 0.001 & 0.003 & 0.005 & - & $\underline{0.240}$ & \\
\hline & $\mathrm{M}$ & 0.009 & -0.003 & 0.004 & 0.003 & -0.001 & 0.006 & - & \\
\hline \multirow[t]{8}{*}{2007} & $\mathrm{BN}$ & - & 0.189 & 0.185 & $\underline{0.203}$ & $\underline{0.212}$ & $\underline{0.265}$ & $\underline{0.198}$ & \\
\hline & BS & 0.000 & - & $\underline{0.188}$ & 0.195 & 0.209 & 0.251 & 0.187 & \\
\hline & $\mathrm{N}$ & 0.001 & 0.002 & - & 0.196 & 0.212 & 0.268 & $\underline{0.188}$ & \\
\hline & $\mathrm{S}$ & 0.004 & 0.004 & 0.005 & - & $\underline{0.222}$ & $\underline{0.257}$ & $\underline{0.198}$ & \\
\hline & $\mathrm{E}$ & $\underline{0.007}$ & 0.004 & $\underline{0.007}$ & $\underline{0.008}$ & - & $\underline{0.252}$ & $\underline{0.198}$ & \\
\hline & $\mathrm{W}$ & 0.027 & $\underline{0.019}$ & 0.035 & 0.024 & $\underline{0.018}$ & - & 0.245 & \\
\hline & $\mathrm{M}$ & $\overline{0.002}$ & $\overline{0.002}$ & $\overline{0.004}$ & $\overline{0.004}$ & $\overline{0.002}$ & $\underline{0.023}$ & - & \\
\hline & & $\mathrm{BN}$ & BS & $\mathrm{N}$ & $\mathrm{S}$ & E & $\mathrm{W}$ & $\mathrm{L}$ & $\mathrm{G}$ \\
\hline \multirow[t]{8}{*}{2008} & $\mathrm{BN}$ & - & $\underline{0.262}$ & $\underline{0.267}$ & $\underline{0.252}$ & $\underline{0.259}$ & $\underline{0.238}$ & $\underline{0.243}$ & $\underline{0.279}$ \\
\hline & BS & 0.007 & - & $\overline{0.270}$ & $\underline{0.265}$ & $\overline{0.261}$ & $\underline{0.228}$ & $\underline{0.250}$ & $\overline{0.271}$ \\
\hline & $\mathrm{N}$ & 0.005 & 0.004 & $\overline{-}$ & $\overline{0.262}$ & $\underline{0.277}$ & $\overline{0.247}$ & $\overline{0.244}$ & $\underline{0.280}$ \\
\hline & $\mathrm{S}$ & 0.003 & 0.002 & 0.000 & $\overline{-}$ & $\overline{0.263}$ & $\overline{0.231}$ & $\overline{0.246}$ & $\underline{0.267}$ \\
\hline & $\mathrm{E}$ & 0.005 & 0.003 & 0.005 & 0.003 & $\overline{-}$ & 0.253 & $\overline{0.258}$ & $\overline{0.286}$ \\
\hline & $\mathrm{W}$ & 0.003 & 0.001 & 0.001 & -0.002 & 0.002 & - & $\overline{0.220}$ & $\underline{0.248}$ \\
\hline & $\mathrm{L}$ & 0.007 & 0.006 & 0.002 & 0.003 & 0.006 & 0.002 & - & $\underline{0.256}$ \\
\hline & $\mathrm{G}$ & 0.011 & 0.003 & 0.008 & 0.006 & 0.000 & 0.003 & 0.007 & - \\
\hline
\end{tabular}

Exact test results indicated that $83 \%$ of populations showed significant changes in allelic composition between successive sampling years $(\mathrm{p}<0.05)$ and $90 \%$ showed differences in genotypic composition between successive years. Mantel tests showed no significant relationships between adult population structure in successive sampling periods (Mantel: $\mathrm{p}>0.05$ ) either using $D_{\mathrm{C}}$ or $D_{\mathrm{EST}}$ as a measure, or between juvenile population structure in one year to adult population structure in the following year (Mantel: $p>0.05$ ). Comparisons of juvenile population structure across years also showed no significant relationships (Mantel: $\mathrm{p}>0.05$ ).

\section{Explaining chaotic genetic patchiness}

We found no evidence of either positive or disruptive selection acting on our loci in either adult or juvenile populations as determined by replicate runs in LOSITAN. Comparisons of genetic diversity be- tween adult and juvenile samples yielded no significant differences in either heterozygosity $(t=-0.56$, $\mathrm{df}=8, \mathrm{p}=0.59$; Table 1$)$ or allelic richness $(t=-0.18$, $\mathrm{df}=8, \mathrm{p}=0.45$; Table 1). Exact tests showed differentiation between almost all juvenile samples and their corresponding adult populations across all years (24 of 29 comparisons, $\mathrm{p}<0.05$; Table 4). Furthermore, we found no relationship between adult and juvenile genetic structure $\left(F_{1,87}=0.158, \mathrm{r}^{2}=0.001, \mathrm{p}=0.69\right.$; Fig. 3). We found that all mean relatedness values were low $(<0.005)$, however the relatedness among adults was significantly greater than that among juveniles $(t=2.77, \mathrm{df}=56, \mathrm{p}=0.007$; Fig. 4). Regression of mean pair-wise $D_{\mathrm{C}}$ against mean relatedness in the juvenile samples showed no relationship ( $F=$ 0.49, df = 28, p = 0.48; Fig. 4).

Both adult and juvenile size distributions were approximately normal across all samples, (adults: mean $=51.5$, median $=52.5$, mode $=52.0$; juveniles: mean $=20.7$, median $=21.0$, mode $=21.0$ ). We divided all samples into 
Table 4. Comparisons of juvenile and adult population genetic structure of Stegastes partitus (see Fig. 1 for population abbreviations). Significant values are indicated in bold and underlined. nd indicates no data

\begin{tabular}{|c|c|c|c|c|c|c|c|c|}
\hline & \multicolumn{2}{|c|}{2005} & \multicolumn{2}{|c|}{2006} & \multicolumn{2}{|c|}{2007} & \multicolumn{2}{|c|}{2008} \\
\hline & $F_{\mathrm{ST}}$ & Exact test & $F_{\mathrm{ST}}$ & Exact test & $F_{\mathrm{ST}}$ & Exact test & $F_{\mathrm{ST}}$ & Exact test \\
\hline $\mathrm{BN}_{\text {Adult }}$ Vs. BN $\mathrm{BNuv}_{\text {Juv }}$ & 0.005 & $\leq \underline{0.001}$ & 0.003 & $\underline{0.001}$ & $\underline{0.007}$ & $\leq \underline{0.001}$ & 0.005 & $\leq \underline{0.001}$ \\
\hline $\mathrm{BS}_{\text {Adult }}$ vs. $\mathrm{BS}_{\text {Juv }}$ & $\underline{0.008}$ & $\underline{0.014}$ & 0.003 & $\overline{0.003}$ & $\overline{0.006}$ & $\leq \underline{0.001}$ & 0.001 & $\underline{0.010}$ \\
\hline $\mathrm{N}_{\text {Adult }}$ Vs. $\mathrm{N}_{\text {Juv }}$ & $\overline{0.000}$ & $\overline{0.002}$ & 0.002 & $\overline{0.270}$ & $\overline{0.013}$ & $\leq \overline{0.001}$ & 0.007 & $\leq \overline{0.001}$ \\
\hline $\mathrm{S}_{\text {Adult }}$ Vs. $\mathrm{S}_{\text {Juv }}$ & 0.006 & $\leq \overline{0.001}$ & 0.002 & 0.103 & $\overline{0.021}$ & $\leq \overline{0.001}$ & 0.004 & $\overline{0.010}$ \\
\hline$E_{\text {Adult }}$ vs. $E_{\text {Juv }}$ & 0.008 & $\underline{0.017}$ & 0.004 & $<\underline{0.001}$ & $\overline{0.004}$ & $\leq \underline{0.001}$ & 0.002 & $\overline{\underline{0.048}}$ \\
\hline $\mathrm{W}_{\text {Adult }}$ vs. $\mathrm{W}_{\text {Juv }}$ & 0.007 & $\leq \overline{0.001}$ & 0.002 & $\underline{0.010}$ & $\underline{0.025}$ & $\leq 0.001$ & $\underline{0.008}$ & $\leq \overline{0.001}$ \\
\hline$M_{\text {Adult }}$ vs. $M_{\text {Juv }}$ & 0.004 & 0.015 & 0.003 & 0.001 & 0.000 & 0.175 & nd & nd \\
\hline $\mathrm{L}_{\text {Adult }}$ VS. $\mathrm{L}_{\text {Juv }}$ & nd & nd & nd & nd & nd & nd & 0.003 & $\underline{0.005}$ \\
\hline $\mathrm{G}_{\text {Adult }}$ vs. $\mathrm{G}_{\text {Juv }}$ & nd & nd & nd & nd & nd & nd & 0.006 & $\leq \underline{0.001}$ \\
\hline
\end{tabular}

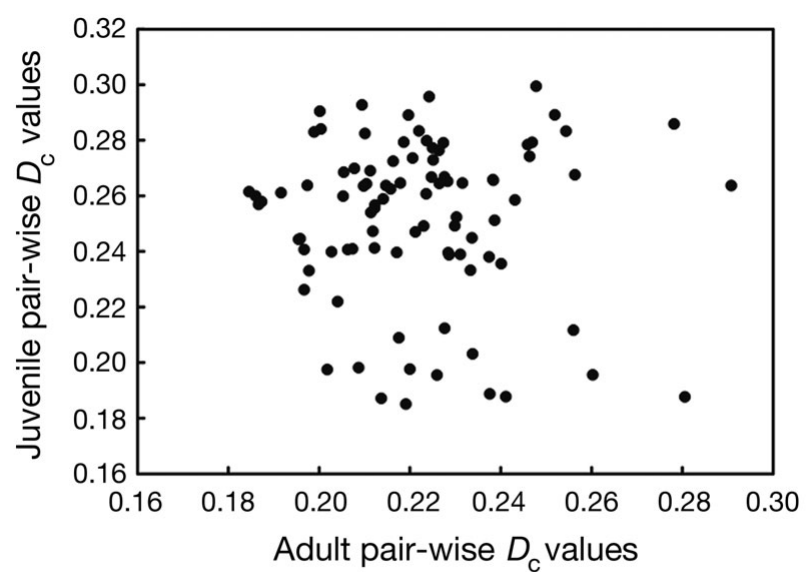

Fig. 3. Testing for pre-settlement effects as the cause of chaotic genetic patchiness. Scatterplot of pair-wise $D_{\mathrm{C}}$ values comparing adult and juvenile populations of Stegastes partitus sampled at 10 sites over $4 \mathrm{yr}$ on the Mesoamerican barrier reef. If pre-settlement effects are driving chaotic genetic structure we expect to see discordance between adult and juvenile genetic structure

small and large groups. Small adults were $<52 \mathrm{~mm}$ and large adults were $\geq 52 \mathrm{~mm}$. Small juveniles were $<21 \mathrm{~mm}$ and large juveniles were $\geq 21 \mathrm{~mm}$. After dividing the samples into size classes, we analysed these 'populations' for goodness of fit to HWE. Both small and large adult and juvenile samples showed deviations from HWE, at various loci, in 32, 31, 27 and $19 \%$ of tests in 2005, 2006, 2007 and 2008 respectively (prior to Bonferroni correction). These values were reduced by an average of $9.5 \%$ compared to the populations with the size classes pooled together (see above).

\section{DISCUSSION}

In this study, we show weak but significant population genetic structure among populations of Stegastes partitus (e.g. Fig. 2) in the Mesoamerican Barrier Reef
System (MBRS). However, we found no evidence of an equilibrium spatial pattern in genetic structure (i.e. no isolation by distance). Previous studies have found mixed evidence for population structuring in $S$. partitus. Lacson (1992) found no genetic structure across the entire Caribbean using allozyme markers and OspinaGuerrero et al. (2008) found similar results using microsatellite markers in the Colombian-Caribbean. However, other studies found genetic heterogeneity among populations of $S$. partitus in the Florida Keys (Lacson et al. 1989), but the differentiation was attributed to population bottlenecks (Lacson \& Morizot 1991). Furthermore, recent microsatellite analyses showed weak population structuring within the Caribbean Antilles (Purcell et al. 2009), the Bahamas (Christie et al. 2010) and within the western Caribbean (Salas et al. 2009). Studies also showed that genetic structure was unstable at seasonal (2 mo: Hepburn et al. 2009) and annual (Hepburn et al. 2009, Christie et al. 2010) temporal scales in both adults and juveniles.

More generally, strong population differentiation has been shown in some reef fishes (Bernardi 2000, Planes et al. 2001, Hoffman et al. 2005), however many of these species have limited dispersal capabilities due to their lack of pelagic larval stages. A study of 7 coral reef fishes showed that genetic structure was inversely related to pelagic larval duration (PLD), and the authors suggested that species with larval durations greater than 1 mo should tend toward panmixia (Doherty et al. 1995). This was also supported by a meta-analysis of 44 species of diverse marine organisms (Shanks 2009). Studies of other common Caribbean reef fishes with long PLDs have found no evidence of population genetic structure, even at large scales (Shulman \& Bermingham 1995, Rocha et al. 2002, Haney et al. 2007). Although some species with significant PLDs show population genetic structure, the spatial scale between divergent populations is typically large (100s to 1000 s of km: Bernardi et al. 2001, Purcell et al. 2006). 

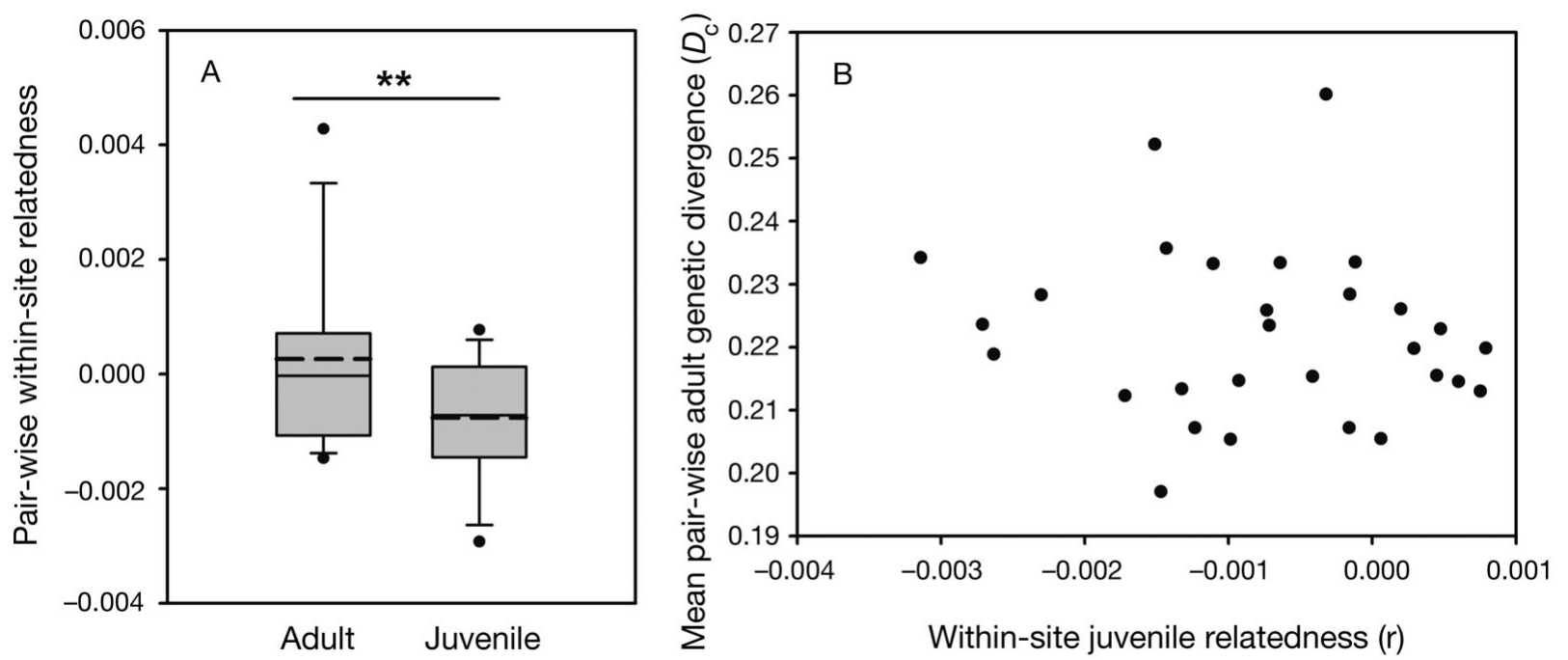

Fig. 4. Testing predictions of the sweepstakes-chance matching hypothesis, which predicts that juvenile samples will have higher within-site relatedness than adult samples and that juveniles will be more related in genetically differentiated populations, as the observed differentiation would be the result of an influx of juveniles produced by a discrete subset of an adult population. (A) Box-whisker plot describing the mean (dashed line) and median (solid line) pair-wise within-site relatedness of adult samples and juvenile samples. The borders of the box indicate the 25 th and 75 th percentiles. The whiskers indicate the 10 th and 90 th percentiles and the dots indicate the 5th and 95th percentiles. ${ }^{* *}$ indicates a significant difference in the mean relatedness between adult and juvenile samples. (B) The relationship between juvenile within-site relatedness and mean adult population genetic divergence $\left(D_{\mathrm{c}}\right)$

Many of the populations studied here deviated from HWE at multiple loci. Deviations were caused almost always by heterozygote deficiencies. This result was mirrored in other recent studies of Stegastes partitus using various microsatellite loci (Ospina-Guerrero et al. 2008, Hepburn et al. 2009, Purcell et al. 2009, Salas et al. 2009, Christie et al. 2010), as well as in other reef fishes (e.g. Purcell et al. 2006). Despite deviations from equilibrium at some loci, no population systematically deviated from HWE at all loci. Furthermore, we found temporal variation in the pattern of departure from HWE within populations, with populations departing from HWE at a locus in one year and adhering to HWE in the next year: such variation is not consistent with high null allele frequencies. Rather, this more likely reflects the strong temporal variation in population genetic structure observed in our study (Fig. 2), indicated by changes in allele frequencies within reefs between years and a lack of temporal correlation in population genetic structure. Indeed, other studies of $S$. partitus using microsatellite markers have also noted a lack of temporal genetic stability (Hepburn et al. 2009, Christie et al. 2010).

The type of genetic heterogeneity reported here, characterized by weak spatial genetic structure and high levels of temporal variation, coupled with temporally variable deviations from HWE, is quite common in marine systems and has been termed 'chaotic genetic patchiness' (Johnson \& Black 1982, Hedgecock 1994). There have been several hypotheses put forth to ex- plain chaotic genetic patchiness in marine organisms (see Larson \& Julian 1999). These hypotheses include pre-settlement selection, post-settlement selection, 'sweepstakes chance-matching' (Hedgecock 1994) and variable sources of larvae. We can use our data to test these hypotheses to determine which mechanisms are likely contributing to the chaotic genetic patchiness in this system.

Selection either pre- or post-settlement can lead to variable adult and juvenile genetic structure and can explain genetic patchiness. However, it is unlikely that pre- or post-settlement selection is causing the observed genetic patchiness among populations of Stegastes partitus in this study because neutral microsatellite markers are insensitive to natural selection, and it is unlikely that selection would occur across all 9 unlinked loci (Christie et al. 2010). Our markers show no evidence of linkage with functional loci under selection as indicated by consistently low global $F_{\mathrm{ST}}$ values across loci (our Table 1; Heath et al. 2006). Furthermore, analysis using the Beaumont \& Nichols (1996) algorithm showed no evidence of selection effects on these loci in either adult or juvenile populations.

Pre-settlement processes leading to variable larval cohort composition can explain genetic patchiness. Larval cohort composition can vary either spatially or temporally, and each provides information on the likely mechanism of connectivity. Spatial variability would result from predictable larval dispersal from differentiated upstream sources to a settlement site and 
would produce relatively temporally stable juvenile and adult genetic structure. However, we found considerable temporal change in population structure, both between years and life stages (adults vs. juveniles). Temporal genetic stability among populations is expected when either isolation, or a consistent and predictable pattern of gene flow, is present (Purcell et al. 2006). Stegastes partitus populations in the MBRS are unlikely to be isolated, as indicated by low $F_{\mathrm{ST}}$ values. Thus, given the temporal variation in adult and juvenile genetic structure, temporal variation in recruit cohort genetic structure is likely to be a major contributor to our observed genetic patchiness. Such temporal variability in cohort composition may be the result of 2 possible mechanisms; the generation of different cohorts over time via sweepstakes effects or changing sources of recruits resulting from stochastic larval transport processes (i.e. variable source hypothesis).

The sweepstakes hypothesis was first proposed by Hedgecock (1994) as a mechanism capable of generating cohort variability, and has been invoked to explain genetic patchiness within and among populations of Stegastes partitus in the Bahamas (Christie et al. 2010). Under this model, high reproductive variance in adult populations caused by locally variable spawning conditions and larval survival produces an instantaneous drift effect on the composition of larval populations. This variability leads to spatial and temporal genetic patchiness as these larval cohorts recruit into adult populations. One prediction of this hypothesis is that we should observe reduced genetic variability in juvenile populations relative to the adults since larvae have been produced by only a subset of the total adult population (while adult populations are integrated over multiple recruitment events). For example, Pacific oysters (Crassostrea gigas) show decreased genetic diversity in settling larvae attributed to variability in adult reproductive success (Li \& Hedgecock 1998). Our data allow us to test specifically for the sweepstakes hypothesis; however, they do not support this hypothesis as we found no difference in genetic variability in juveniles relative to adults as measured by either observed heterozygosity or allelic richness at 9 microsatellite loci.

A second prediction of the sweepstakes hypothesis is that recently settled cohorts should exhibit elevated levels of kinship relative to adult populations. This was reported to occur in kelp bass (Paralabrax clathratus) populations in California, providing evidence for sweepstakes effects in those populations (Selkoe et al. 2006). However, we found that pair-wise within site relatedness was significantly higher in adult samples relative to the juvenile cohorts. Again, this result is contrary to that expected by the sweepstakes hypothesis.

One additional prediction of the sweepstakes hypothesis is that the juvenile cohorts that are most genetically divergent should also exhibit higher relatedness. That is, we would expect to see a positive relationship between average population genetic distance in the adults and the within-population relatedness in recently settled juveniles. This is due to population differentiation being driven by the influx of cohorts of highly related individuals. Our results indicate no relationship between relatedness and genetic distance. Thus, our data suggest that it is unlikely that sweepstakes effects are playing the major role in driving the patterns of genetic divergence and temporal instability we observed.

The variable source hypothesis could result in the pattern of genetic divergence in this system. Under this model, recruits arriving at a site over time would vary in their source population(s) due to stochastic processes affecting their dispersal pathway or survival (Cowen et al. 2000). If this were the case, we would expect to see temporally variable genetic structure in juvenile and adult populations, and no predictive relationship between adult and juvenile genetic structure within sites. We would also expect to see evidence of a Wahlund effect characterized by deviations from HWE as a result of homozygote excess. Our results support this hypothesis, as we have shown temporally variable genetic structure in both adult and juvenile populations, and perhaps more importantly, a lack of concordance between the two life stages. Such stochastic variation in the composition of recruiting cohorts would result in non-equilibrium population genetics, since each site would not technically constitute a 'population' but rather an admixture of cohorts from multiple sources. Support for this comes from the nonequilibrium status of most of our sample populations. Our microsatellite loci show variable spatial and temporal patterns of homozygote excesses, consistent with a Wahlund effect, resulting from pooling individuals from multiple sources that exhibit different allele frequencies (Johnson \& Black 1984). Furthermore, since our adult samples consist of multiple cohorts integrated over time, we expect to find greater disequilibrium in the adult samples. Our analysis of the patterns of departure from HWE supports that expectation, since adults showed higher levels of disequilibrium. Also, by dividing our samples into size classes we were able to show a reduction in departures from HWE in the order of approximately one-third, again supporting the idea that our populations are an amalgam of multiple cohorts.

The reproductive life history of Stegastes partitus may explain the magnitude of the disequilibrium in the adult samples. Since $S$. partitus spawn year round, adult populations are potentially comprised of very large numbers of independent larval cohorts. Our data show that recently settled juvenile cohorts can be 
genetically differentiated over time, thus adult $S$. partitus populations may be unusually susceptible to Wahlund effects. Although our data indicate that temporally stochastic larval dispersal patterns are the likely dominant factor in our observed temporal and spatial patterns of genetic divergence in $S$. partitus, the nature of the process driving the variation in recruit composition is unknown.

Temporal changes in oceanographic flow may explain some of the patterns of differentiation seen in Stegastes partitus populations along the MBRS, and has been shown to influence population dynamics (McShane et al. 1988, Lee \& Williams 1999) and shape population genetic structure in other species and systems (Kenchington et al. 2006, Selkoe et al. 2006). Furthermore, the MBRS experiences considerable variability in flow, both in velocity and direction of currents seasonally (Ezer et al. 2005, Cowen et al. 2006, Tang et al. 2006).

The results of this study are contrary to a recent study of Stegastes partitus populations (Christie et al. 2010) which also reported chaotic genetic patchiness but in Bahamian populations. Christie et al. (2010) reported support for the sweepstakes hypothesis, showing higher diversity and lower relatedness within adult populations relative to juvenile samples. They also found evidence for possibly high levels of selfrecruitment to the sampled Bahamian reefs. There is evidence from coupled oceanographic-genetic models (Galindo et al. 2006) and coupled biophysical models (Cowen et al. 2006) to suggest that the Bahamas is an area of greater retention relative to the MBRS, which is more open and connected. Phylogeographic studies of the Caribbean have shown that there are strong biogeographic breaks in the Bahamas created by oceanographic barriers to dispersal, but not so in the MBRS (Taylor \& Hellberg 2006), and earlier work has shown direct evidence of high levels of self-recruitment to reefs in the Bahamas (Swearer et al. 1999). Population genetic studies have found that the populations in the MBRS and the western Caribbean in general tend to be well mixed (Purcell et al. 2009, Salas et al. 2010). The different oceanographic environments in these 2 regions may affect the processes driving the replenishment of populations of $S$. partitus, such that the open MBRS system is characterised by variable connectivity among reefs and the reefs in the Bahamas are characterised by self-recruitment and sweepstakes effects.

The variability in connectivity inferred from our results has important implications for the ecology and management of marine populations. Irregularity in connectivity among populations in a meta-population framework promotes stability of the metapopulation and buffers against strong fluctuations in population sizes (Holland \& Hastings 2008). However, as connec- tivity among populations is likely to vary through time, it is difficult to predict which populations will be likely sources of larvae to surrounding areas. In the cases where there is highly variable connectivity among populations, it is in the best interest of marine managers to employ a spatial bet-hedging strategy (Larson \& Julian 1999) using a network of smaller reserves distributed throughout a region, in order to increase the likelihood of protecting critical populations and account for the variability in connectivity through time. Such a strategy that preserves some of the spatial heterogeneity of habitats will help promote stability within populations and buffer against population extinctions.

Acknowledgements. We thank D. Hasselman, C. Nolan, E. Salas, M. Smith, P. Usseglio, and R. Walter for assistance during collections, C. Beneteau, R. Hepburn, and E. Salas for assistance in the lab, J. Muirhead for technical support and P.F. Sale and D. Campbell-Smith for logistical support. This work was supported by Natural Sciences and Engineering Research Council of Canada grants, and funds from the Connectivity program of the GEF Coral Reef Targeted Research project to D.D.H.

\section{LITERATURE CITED}

Antao T, Lopes A, Lopes RJ, Beja-Pereira A, Luikart G (2008) LOSITAN: A workbench to detect molecular adaptation based on a $F_{\mathrm{ST}}$-outlier method. BMC Bioinformatics 9:323

$>$ Beaumont MA, Nichols RA (1996) Evaluating loci for use in genetic analysis of population structure. Proc Biol Sci 263: $1619-1626$

> Bernardi G (2000) Barriers to gene flow in Embiotoca jacksoni, a marine fish lacking a pelagic larval stage. Evolution 54:226-237

Bernardi G, Holbrook SJ, Schmitt RJ (2001) Gene flow at three spatial scales in a coral reef fish, the three-spot dascyllus, Dascyllus trimaculatus. Mar Biol 138:457-465

Bradbury IR, Laurel B, Snelgrove PVR, Bentzen P, Campana SE (2008) Global patterns in marine dispersal estimates: the influence of geography, taxonomic category and life history. Proc Biol Sci 275:1803-1809

Cavalli-Sforza LL, Edwards AW (1967) Phylogenetic analysis: models and estimation procedures. Am J Hum Genet 19: 233-257

> Christie MR, Johnson DW, Stallings CD, Hixon MA (2010) Self-recruitment and sweepstakes reproduction amid extensive gene flow in a coral-reef fish. Mol Ecol 19: 1042-1057

Cowen RK, Lwiza KMM, Sponaugle S, Paris CB, Olson DB (2000) Connectivity of marine populations: open or closed? Science 287:857-859

Cowen RK, Paris CB, Srinivasan A (2006) Scaling of connectivity in marine populations. Science 311:522-527

Cowen RK, Gawarkiewicz G, Pineda J, Thorrold SR, Werner FE (2007) Population connectivity in marine systems: an overview. Oceanography 20:14-21

$>$ Crawford NG (2010) SMOGD: software for the measurement of genetic diversity. Mol Ecol Res 10:556-557

$>$ Dieringer D, Schlötterer C (2003) MICROSATELLITE ANALYSER (MSA): a platform independent analysis tool 
for large microsatellite data sets. Mol Ecol Notes 3: 167-169

Doherty PJ, Williams DMcB (1988) The replenishment of coral reef fish populations. Oceanogr Mar Biol Annu Rev 26: 487-551

Doherty PJ, Planes S, Mather P (1995) Gene flow and larval duration in seven species of fish from the Great Barrier Reef. Ecology 76:2373-2391

Elphinstone MS, Hinten GN, Anderson MJ, Nock CJ (2003) An inexpensive and high-throughput procedure to extract and purify total genomic DNA for population studies. Mol Ecol Notes 3:317-320

Excoffier L, Laval G, Schneider S (2005) Arlequin ver. 3.0: An integrated software package for population genetics data analysis. Evol Bioinform Online 1:47-50

$>$ Ezer T, Thattai DV, Kjerfve B, Heyman WD (2005) On the variability of the flow along the Meso-American barrier reef system: a numerical model study of the influence of the Caribbean current and eddies. Ocean Dyn 55:458-475

Galindo HM, Olson DB, Palumbi SR (2006) Seascape genetics: a coupled oceanographic-genetic model predicts population structure of Caribbean corals. Curr Biol 16: $1622-1626$

Haney RA, Silliman BR, Rand DM (2007) A multi-locus assessment of connectivity and historical demography in the bluehead wrasse (Thalassoma bifasciatum). Heredity 98 : 294-302

Heath DD, Shrimpton JM, Hepburn RI, Jaimeson SK, Brode SK, Docker MF (2006) Population structure and divergence using microsatellite and gene locus markers in Chinook salmon (Oncorhyncus tshawytscha) populations. Can J Fish Aquat Sci 63:1370-1383

Hedgecock D (1994) Temporal and spatial genetic structure of marine animal populations in the California current. CalCOFI 35:73-81

Hedgecock D, Barber PH, Edmands S (2007) Genetic approaches to measuring connectivity. Oceanography 20: $70-79$

> Hepburn RI, Sale PF, Dixon B, Heath DD (2009) Genetic structure of juvenile cohorts of Bicolor damselfish (Stegastes partitus) along the Mesoamerican barrier reef: chaos through time. Coral Reefs 28:277-288

Hilbish TJ (1996) Population genetics of marine species: the interaction of natural selection and historically differentiated populations. J Exp Mar Biol Ecol 200:67-83

- Hoffman EA, Kolm N, Berglund A, Arguello JR, Jones AG (2005) Genetic structure in the coral-reef-associated Banggai cardinalfish, Pterapogon kauderni. Mol Ecol 14: 1367-1375

Hogan JD (2007) Behaviour, recruitment and dispersal of coral reef fish larvae: insight into the larval life stage. $\mathrm{PhD}$ thesis, University of Windsor, Canada.

> Holland MD, Hastings A (2008) Strong effect of dispersal network structure on ecological dynamics. Nature 456: 792-795

> Johannesson K, Johannesson B, Lundgren U (1995) Strong natural selection causes microscale allozymes variation in a marine snail. Proc Natl Acad Sci USA 92:2602-2606

Johnson MS, Black R (1982) Chaotic patchiness in an intertidal limpet, Siphonaria sp. Mar Biol 70:157-164

> Johnson MS, Black R (1984) Pattern beneath the chaos: the effect of recruitment on genetic patchiness in an intertidal limpet. Evolution 38:1371-1383

> Jones GP, Almany GR, Russ GR, Sale PF, Steneck RS, van Oppen MJH, Willis BL (2009) Larval retention and connectivity among populations of corals and reef fishes: history, advances and challenges. Coral Reefs 28:307-325
Jost L (2008) $\mathrm{G}_{\mathrm{ST}}$ and its relatives do not measure differentiation. Mol Ecol 17:4015-4026

Kenchington EL, Patwary MU, Souros E, Bird CJ (2006) Genetic differentiation in relation to marine landscape in a broadcast-spawning bivalve mollusc (Placopecten magellanicus). Mol Ecol 15:1781-1796

> Lacson JM (1992) Minimal genetic variation among samples of six species of coral reef fishes collected at La Parguera, Puerto Rico, and Discovery Bay, Jamaica. Mar Biol 112: 327-331

> Lacson JM, Morizot DC (1991) Temporal genetic variation in subpopulations of Bicolor damselfish (Stegastes partitus) inhabiting coral reefs in the Florida Keys. Mar Biol 110: 353-357

> Lacson JM, Riccardi VM, Calhoun SW, Morizot DC (1989) Genetic differentiation of Bicolor damselfish (Eupomacentrus partitus) populations in the Florida Keys. Mar Biol 103:445-451

Larson RJ, Julian RM (1999) Spatial and temporal genetic patchiness in marine populations and their implications for fisheries management. CalCOFI 40:94-99

Lee TN, Williams E (1999) Mean distribution and seasonal variability of coastal currents and temperature in the Florida Keys with implications for larval recruitment. Bull Mar Sci 64:35-56

Li G, Hedgecock D (1998) Genetic heterogeneity, detected by PCR SSCP, among samples of larval Pacific oysters (Crassostrea gigas) supports the hypothesis of large variance in reproductive success. Can J Fish Aquat Sci 55:1025-1033

- Lynch M, Ritland K (1999) Estimation of pairwise relatedness with molecular markers. Genetics 152:1753-1766

> McShane PE, Black KP, Smith MG (1988) Recruitment process in Haliotis rubra (Mollusca: Gastropoda) and regional hydrodynamics in southeastern Australia imply localized dispersal of larvae. J Exp Mar Biol Ecol 124:175-203

Myrberg AA (1972) Ethology of the bicolor damselfish, Eupomacentrus partitus: a comparative analysis of laboratory and field behaviour. Anim Behav Monogr 5:197-283

Ospina-Guerrero SP, Landinez-García RM, Rodríguez-Castro DJ, Arango R, Márquez E (2008) Genetic connectivity of Stegastes partitus in the South Caribbean evidenced by microsatellite analysis. Cienc Mar 34:155-163

Peakall R, Smouse PE (2006) GENALEX 6: genetic analysis in Excel. Population genetic software for teaching and research. Mol Ecol Notes 6:288-295

> Planes S, Doherty PJ, Bernardi G (2001) Strong genetic divergence among populations of a reef fish with limited dispersal, Acanthochromis polyacanthus, within the Great Barrier Reef and the Coral Sea. Evolution 55:2263-2273

Purcell MK, Kornfield I, Fogarty M, Parker A (1996) Interdecadal heterogeneity in mitochondrial DNA of Atlantic haddock (Melanogrammus aeglefinus) from Georges Bank. Mol Mar Biol Biotechnol 5:185-192

Purcell JFH, Cowen RK, Hughes CR, Williams DA (2006) Weak genetic structure indicates strong dispersal limits: a tale of two coral reef fish. Proc Biol Sci 273:1483-1490

> Purcell JFH, Cowen RK, Hughes CR, Williams DA (2009) Population structure in a common Caribbean reef fish: implications for larval dispersal and early life-history traits. J Fish Biol 74:403-417

Queller DC, Goodnight KF (1989) Estimating genetic relatedness using genetic markers. Evolution 43:258-275

Raymond M, Rousset F (1995) GENEPOP (version 1.2): population genetics software for exact tests and ecumenicism. J Hered 86:248-249

$>$ Rice WR (1989) Analyzing tables of statistical tests. Evolution 43:223-225 
Roberts CM (1997) Connectivity and management of Caribbean coral reefs. Science 278:1454-1457

Robertson DR, Green DG, Victor BC (1988) Temporal coupling of production and recruitment of larvae of a Caribbean reef fish. Ecology 69:370-381

Rocha LA, Bass AL, Robertson DR, Bowen BW (2002) Adult habitat preferences, larval dispersal, and the comparative phylogeography of three Atlantic surgeonfishes (Teleostei: Acanthuridae). Mol Ecol 11:243-252

Salas E, Molina-Urena H, Walter RP, Heath DD (2010) Local and regional genetic connectivity in a Caribbean coral reef fish. Mar Biol 157:437-445

Selkoe KA, Gaines SD, Caselle JE, Warner RR (2006) Current shifts and kin aggregation explain genetic patchiness in fish recruits. Ecology 87:3082-3094

Shanks AL (2009) Pelagic larval duration and dispersal distance revisited. Biol Bull 216:373-385

Shulman MJ, Bermingham E (1995) Early life histories, ocean currents, and the population genetics of Caribbean reef fishes. Evolution 49:897-910

Swearer SE, Caselle JE, Lea DW, Warner RR (1999) Larval retention and recruitment in an island population of coral reef fish. Nature 402:799-802

Tang L, Sheng J, Hatcher BG, Sale PF (2006) Numerical study of circulation, dispersion and hydrodynamic connectivity of surface waters on the Belize shelf. J Geophys Res 111: C01003 doi:10.1029/2005JC002930

Taylor MS, Hellberg ME (2006) Comparative phylogeo-

Editorial responsibility: Nicholas Tolimieri,

Seattle, Washington, USA graphy in a genus of coral reef fishes: biogeographic and genetic concordance in the Caribbean. Mol Ecol 15: 695-707

> Thiessen RJ, Heath DD (2007) Characterization of one trinucleotide and six dinucleotide microsatellite markers in Bicolor damselfish, Stegastes partitus, a common coral reef fish. Conserv Genet 8:983-985

Van Oosterhout C, Hutchison WF, Wills DPM, Shipley P (2004) Micro-checker: software for identifying and correcting genotyping errors in microsatellite data. Mol Ecol Notes 4:535-538

Waples RS (1987) A multispecies approach to the analysis of gene flow in marine shore fishes. Evolution 41:385-400

> Ward RD, Woodwark M, Skibinski DOF (1994) A comparison of genetic diversity levels of marine, freshwater and anadromous fishes. J Fish Biol 44:213-232

Watts RJ, Johnson MS, Black R (1990) Effects of recruitment on genetic patchiness in the urchin Echinometra mathaei in Western Australia. Mar Biol 105:145-151

> Wellington GM, Victor BC (1989) Planktonic larval duration of one hundred species of Pacific and Atlantic damselfishes (Pomacentridae). Mar Biol 101:557-567

> Williams DA, Purcell J, Hughes CR, Cowen RK (2003) Polymorphic microsatellite loci for population studies of the Bicolor damselfish, Stegastes partitus (Pomacentridae). Mol Ecol Notes 3:547-549

- Wright S (1931) Evolution in Mendelian populations. Genetics 16:97-158

Submitted: March 31, 2010; Accepted: August 23, 2010

Proofs received from author(s): October 18, 2010 